\title{
The Potential of an Artificial Intelligence for Disability Advocacy: The WikiDisability Project
}

\author{
Rachel GORMAN a ${ }^{\text {, Pierre MARET }}{ }^{\mathrm{b}}$, Alexandra CREIGHTON ${ }^{\mathrm{a}}$, Bushra KUNDI a, \\ Fabrice MUHLENBACH $^{\mathrm{b}}$, Alexis BUETTGEN ${ }^{\mathrm{c}}$, Enakshi DUA ${ }^{\mathrm{d}}$, \\ Geoffrey REAUME ${ }^{\text {a }}$, Thumeka MGWIGWI ${ }^{\mathrm{e}}$, \\ Serban DINCA-PANAITESCU ${ }^{a}$ and Christo EL MORR ${ }^{\text {a, } 1}$ \\ ${ }^{a}$ York University, School of Health Policy and Management, Canada \\ ${ }^{\mathrm{b}}$ Université Jean Monnet Saint Etienne, France \\ ${ }^{\mathrm{c}}$ Canadian Centre on Disability Studies, Inc. operating as Eviance, Canada \\ d School of Gender, Sexuality and Women's Studies, York University, Canada \\ ${ }^{\mathrm{e}}$ Library, York University, Canada
}

\begin{abstract}
Human rights monitoring for people with disabilities is in urgent need for disability data that is shared and available for local and international disability stakeholders (e.g., advocacy groups). Our aim is to use a Wikibase for editing, integrating, storing structured disability related data and to develop a Natural Language Processing (NLP) enabled multilingual search engine to tap into the wikibase data. In this paper, we explain the project first phase.
\end{abstract}

Keywords. Machine learning, wikibase, disability, critical disability, advocacy, health informatics, disability informatics

\section{Introduction}

While reports about people with disabilities much of the available data (e.g., reports, raw data, case laws) is scattered [1]; the lack of availability of disability data has been identified as a major challenge hindering continuous disability rights monitoring [2,3] and exposing systemic discrimination [4]. Health informatics [5], machine learning [6], particularly Natural Language Processing (NLP) [7], can enable users to search for data [8-10] and find semantic similarities within disparate documents[11,12]. Our project aims to create a bilingual wikibase with a smart natural language search capability.

\section{Methods}

Deliberation between content experts in critical disability and the health informatics and computer science professionals, has led to an iterative definition of the domain and scope of the Convention on the Rights of Persons with Disabilities (CRPD) ontology.

\footnotetext{
${ }^{1}$ Corresponding Author, Christo El Morr, School of Health Policy and Management, York University, 4700 Keele St, Toronto, Ontario Canada M3J 1P3; E-mail: elmorr@yorku.ca ORCID: 0000-0001-6287-3438.
} 


\section{Results}

The CRPD ontology is flexible to accommodate the CRPD articles in relation to disability legislations proper to specific jurisdictions and can be expanded to fit international contexts. The platform would have two types of users: information producer and information consumers. Information producers would be to upload data files to the platform. Information consumers would be able to use the platform smart search engine to search for documents using natural language.

\section{Discussion}

Multidisciplinary research in the domain of disabilities is challenging. An iterative process done in a collaborative atmosphere allows team members to elucidate ambiguities and for the team to face challenges and provide solutions.

\section{Conclusion}

Machine learning approaches are promising tools to address disability advocacy data needs. A first version of the CRPD ontology has been developed and the disability wikibase platform is underway.

\section{References}

[1] United Nations. UN Convention on the Rights of Persons with Disabilities New York: Department of Economic and Social Affairs Disability, United Nations; 2006 [cited 2020 July 15].

[2] Loeb M. Disability statistics: an integral but missing (and misunderstood) component of development work. Nord J Hum Rights. 2013;31(3):306-24. PubMed PMID: 26925181.

[3] Abualghaib O, Groce N, Simeu N, Carew MT, Mont D. Making Visible the Invisible: Why DisabilityDisaggregated Data is Vital to "Leave No-One Behind". Sustainability. 2019; 11(11):3091. doi: 10.3390/su11113091.

[4] Rioux MH, Parekh G. Disability, Rights Monitoring, and Social Change: Canadian Scholars' Press; 2015.

[5] El Morr C. Introduction to Health Informatics: A Canadian Perspective. Toronto, Canada: Canadian Scholars' Press; 2018. 354 p.

[6] El Morr C, Ali-Hassan H. Analytics in Healthcare: A Practical Introduction. Tan JK, editor. Cham, Switzerland: Springer International Publishing; 2019. 105 p.

[7] Chowdhary KR. Natural Language Processing. In: Chowdhary KR, editor. Fundamentals of Artificial Intelligence. New Delhi: Springer India; 2020. p. 603-49.

[8] Edgcomb JB, Zima B. Machine Learning, Natural Language Processing, and the Electronic Health Record: Innovations in Mental Health Services Research. Psychiatr Serv. 2019;70(4):346-9. Epub 2019/02/21. doi: 10.1176/appi.ps.201800401. PubMed PMID: 30784377.

[9] Velupillai S, Epstein S, Bittar A, Stephenson T, Dutta R, Downs J. Identifying Suicidal Adolescents from Mental Health Records Using Natural Language Processing. Stud Health Technol Inform. 2019;264:4137. Epub 2019/08/24. doi: 10.3233/shti190254. PubMed PMID: 31437956.

[10] Diefenbach D, Migliatti P, Henrique, Qawasmeh O, Lully V, Singh K, Maret P. QAnswer: A Question Answering prototype bridging the gap between a considerable part of the LOD cloud and end-users. The Web Conference; 2019-05-13; San Francisco, United States2019.

[11] Al-Natsheh HT, Martinet L, Muhlenbach F, Rico F, Zighed DA, editors. Semantic Search-by-Examples for Scientific Topic Corpus Expansion in Digital Libraries. 2017 IEEE International Conference on Data Mining Workshops (ICDMW); 2017 18-21 Nov. 2017.

[12] Bast H, Buchhold B, Haussmann E. Semantic Search on Text and Knowledge Bases. Foundations and Trends in Information Retrieval. 2016;10:119-271. 